\title{
As mudanças nas transmissões esportivas de televisão com a chegada da Super Alta Definição (UHDTV)
}

\author{
Fernando C. Moura
}

\begin{abstract}
A última Copa do Mundo Brasil 2014 mudou a forma de captação, produção e transmissão de jogos de futebol mediante a utilização da tecnologia $4 \mathrm{~K}$, um formato que pode vir a substituir o padrão Full HD utilizado até hoje. Neste artigo relatamos o acompanhamento in loco dos testes realizados durante a Copa das Confederações 2013 e o Mundial 2014, as novidades da implantação do $4 \mathrm{~K}$ e quais as possíveis consequências dessa mudança na retórica do discurso "futebolístico" com a utilização de novas tecnologias de captação, e damos um breve olhar sobre o $8 \mathrm{~K}$, o que pode ainda vir.
\end{abstract}

Index Terms - Ultra HD, Super Hi-Vision, Transmissão ao vivo, Futebol, Narrativa televisiva, $4 \mathrm{~K}, 8 \mathrm{~K}$.

\section{INTRODUÇÃO}

Muito se tem escrito nos últimos anos sobre Ultra Alda Definição 4K (UHD) e 8K Super Hi-Vision (SHV), mas o tema não se esgota nem se esgotará tão depressa. A inovação tecnológica não para, e a corrida pela qualidade de imagem parece não ter fim, ou terá? Essa é uma das perguntas que os estudiosos do tema se fazem e que na opinião de quem escreve, parece não ter resposta ainda.

De fato, com a introdução do $4 \mathrm{~K}$ as transmissões esportivas na última Copa do Mundo realizada no Brasil coordenadas pela FIFA (Federação Internacional de Futebol Associado), e as em $8 \mathrm{~K}$ realizadas experimentalmente pela NHK, o conceito de transmissão esportiva mudou, e muito. E não mudou só a qualidade, mudou a forma retórica de fazer e a parafernália necessária para levar a alguns poucos duas formas de captação de vídeo altamente ricas em qualidade de imagem e imersão, mas também mudou a forma de gerar essas imagens

Nesse marco, afirmamos que o discurso futebolístico é talvez, junto ao melodrama encarnado pela telenovela, o mais difundido na TV nos últimos anos. Ele sustenta emissoras de TV por todo o mundo e aos poucos se tem transformado em quase uma "commodity" que se espalhou nas últimas duas décadas ao redor do mundo.

Assim, após mais de meio século de existência, a TV aberta está mudando, e talvez não pela sua própria vontade, mas sim pelo advento de novas tecnologias e plataformas que permitem ao telespectador - termo que consideramos ultrapassado - usufruir de conteúdos audiovisuais em multiplataformas mediante sistemas de VoD (Video-onDemand), OTT (Over-the-Top), FTH (Direct-to-Home) e plataformas de webTV.

Mas a questão não para por aí. Em 2020, nos Jogos Olímpicos de Tokio, a aposta é transmitir por espectro em $8 \mathrm{~K}$, e nesse momento, talvez aconteça a maior quebra de paradigma das transmissões esportivas dos últimos 50 anos, porque é possível que assistamos a transmissões feitas praticamente com uma só câmera, como eram realizadas as primeiras, mas mudando o conceito e o regime escópico do telespectador.

\section{O fenômeno da TV}

A televisão nasceu em 1936 e expandiu-se após o fim da $2^{\mathrm{a}}$ Guerra Mundial. E com esta cria-se uma nova Galáxia de comunicação.

Não que os outros meios de comunicação desaparecessem, mas foram reestruturados e reorganizados num sistema cujo coração era composto por válvulas eletrônicas e cuja fachada apelativa era uma tela de TV. A rádio perdeu a sua centralidade (...) os filmes foram adaptados para atender às audiências televisivas, com exceção da arte subsidiada pelo governo e dos espetáculos baseados em efeitos especiais das grandes telas. (CASTELLS, 2002, p. 432) 
Mas a invenção de televisão "não foi um fato isolado (...) foi o resultado de um longo processo de investigações e descobrimentos, de experiências e conhecimentos adquiridos" (GIOVANNINI, 1987, p. 35). A sua história tem sido basicamente a necessidade de criar um dispositivo adequado para a exploração das imagens em movimento e o íntimo desejo de refletir a realidade. Segundo Wolton (1994), a televisão possui uma dupla função, de identificação e de representação que não é passiva, e resulta de uma interação constante entre os espectadores e o mundo que é mostrado pela televisão. De alguma maneira, então, a televisão cria a nossa representação do mundo, permite-nos imaginá-lo, estabelece parâmetros e mobiliza as atenções dos seus espectadores. Para alguns, a sua função principal é a de "informar", por isso, Sartori (2000) sustenta que a informação não significa necessariamente conhecimento, pois apenas a informação não faz compreender, pode-se estar informado, mas sem ter a compreensão daquela informação. A televisão dissemina conteúdos por meio de uma linguagem que utiliza o verbal e o não-verbal, por meio de um aparato técnico em constante atualização e avanços tecnológicos. Alguns autores já falam numa linguagem vídeo-tecnológica, na qual se desenvolvem "elementos e combinações semióticas novas e distintivas que começam a ser os sistemas linguísticos do futuro e que se diferenciam dos anteriores a partir da lógica das suas articulações" (OROZCO, 1997, p. 56), dando lugar a uma nova lógica, em que os signos de diversos tipos e procedências se justapõem para construir o espetáculo. É o espetáculo que caracteriza a televisão contemporânea.

\begin{abstract}
Não é a disseminação de informações, apresentadas enganosamente como conhecimentos, não é o objetivo ensinar: o objetivo primeiro da televisão é conquistar, manter e permanentemente ampliar a audiência e, para tanto, é preciso que cada vez mais o espetáculo se faça presente, sempre de maneira original, explorando-se novas combinações de códigos, de gêneros, de estilos que a tecnologia facilita. (OROZCO, 1997, p. 58)
\end{abstract}

\section{Transmissões ao vivo}

A ideia de construção social da realidade foi apresentada por Alfred Schultz durante as décadas de 1940/50, e mais tarde retomada por Thomas Luckmann e Peter Berger (1999). Para os últimos, a linguagem e a comunicação desempenham um papel fundamental na construção da realidade social porque só existirá devido aos mecanismos de relação existentes entre os indivíduos. A realidade difundida pela TV opera como uma seleção e uma construção das informações que são emitidas. Para Bourdieu (2005, p. 14), os produtores de TV (no caso dele, os jornalistas) usam uma espécie de óculos que vêem certas coisas e outras não. Esse princípio de seleção está ligado à busca do sensacional, do espetacular, aquilo que rompa com o habitual, mas que em nada altera as formas de pensar e refletir sobre o mundo. Além disso, a imagem carrega o agravante de poder produzir o que o Bourdieu chama de "efeito do real", ou seja, "poder fazer ver e fazer crer no que faz ver" (2000, p. 14). Portanto, a seleção realizada designa uma forma de censura acerca das ações e discursos transmitidos, moldando o posterior debate público sobre os mesmos.

Para Fechine (2001) a transmissão ao vivo é um formato televisivo que está intrinsecamente associado à simultaneidade entre a realização do acontecimento e sua transmissão.

\footnotetext{
Nessa simultaneidade, está o próprio apelo estético do programa e/ou quadro. $\mathrm{O}$ acontecimento/fato transmitido determina toda a função comunicativa desse tipo de transmissão televisiva, cujo principal atrativo é justamente a imprevisibilidade, a espera pelo inesperado, proporcionados pela simultaneidade entre a produção, transmissão e recepção do fato através da TV (FECHINE, 2001).
}

Esse conjunto de fatores aparentemente eleva as transmissões ao vivo para um patamar de maior importância dentre outros formatos e gêneros televisivos. Um evento ao vivo se caracteriza como algo que deva ser mostrado no exato momento em que acontece, ou então, perde-se o seu valor televisivo. Alguns programas de variedades, shows e etc. estão voltando a ser transmitidos ao vivo por conta da participação popular via aplicativos de segunda tela e nas redes sociais, com o objetivo claro de valorizar e reter a audiência. Soma-se a isso, a qualidade técnica da imagem e do som em $4 \mathrm{~K}$ que se mostra como mais um diferencial do espetáculo.

\section{K, uma nova forma de captação audiovisual}


A tecnologia 4K UHD foi criada pela SONY em 2003, é uma resolução de $3840 \times 2160$ pixels $(8,3$ megapixels) e é uma das duas resoluções da televisão de Ultra Alta Definição (UHDTV). A outra é a 8K UHD, criada pela SONY em parceria com a SHARP especialmente para cinemas do Japão e cinemas da SONY em Hollywood, que é de 7680 pixels $\times$ 4320 pixels ou 33,2 megapixels (Moura, 2014). Assim, o dia 28 de junho de 2014 passou para a história da TV brasileira após a Rede Globo e a Globosat (empresa do grupo Rede Globo) produzirem e transmitirem de forma experimental, ao vivo para o Brasil e o mundo, pela primeira vez na história da televisão, um jogo da Copa do Mundo Brasil 2014 com tecnologia $4 \mathrm{~K}$.

A produção geral do evento esteve a cargo da empresa oficial de captação e transmissão da FIFA, a HBS (Hosting Broadcast Services) que, em conjunto com a Globosat e a Telegenic, trabalharam com suporte integral da Sony, patrocinadora oficial do evento. As transmissões foram realizadas por espectro (TV Globo) e por fibra e via satélite pela Globosat através das operadoras Net, Telefônica-Vivo e Oi no Brasil. As três transmissões realizadas - oitavas-de-final (28 de junho, jogo entre Colômbia e Uruguai), quartas-de-final (4 de julho, com o jogo entre Alemanha e França), e a partida da final da Copa do Mundo (13 de julho) entre Alemanha e Argentina - foram feitas integralmente com tecnologia 4K, já que desde o início até o fim foram utilizados equipamentos com esta tecnologia, ou seja, desde a captação até a produção em uma Unidade Móvel 4K montada especialmente para o evento, a transmissão via satélite até Globosat e as respectivas transmissões via espectro (TV Globo), fibra óptica e satélite para ser recebida por alguns telespectadores. Os três jogos transmitidos com esta tecnologia foram produzidos no Estádio do Maracanã, no Rio de Janeiro, onde foi montado um dispositivo especial, não só técnico e operacional, mas também intelectual para a realização dos jogos. De fato, a transmissão em $4 \mathrm{~K}$ muda, entre muitas coisas, a forma de contar a história do jogo, muda o "discurso futebolístico" e o transforma em um novo discurso, que advém de discursos anteriores, mas tem características próprias que o fazem único.
Para a Copa do Mundo foram utilizadas câmeras F55 de Sony, um equipamento que possui um sensor CMOS de formato nativo $4 \mathrm{~K}$ incluindo um obturador global para eliminar efeitos enviesados de rolamento de obturador e segmentação de flash, entregando vasta gama de cores fiéis para reprodução de cor verdadeira. A câmera possibilita ainda ampla exposição de latitude (14 stops), de alta sensibilidade e baixo ruído. Além de permitir gravação em formato Super $35 \mathrm{~mm}$, com uma resolução nativa de 4096 x 2160 (11,6 milhões de pixels, 8.9 milhões efectivos), com codec XAVC 4K (QFHD) 4:2:2, com um bit rate até 30 fps de $300 \mathrm{Mbps}$, e compressão MPEG-4 AVC/H.264. (Moura, 2014)

Enquanto as transmissões dos 64 jogos da Copa do Mundo foram produzidos com 35 câmeras HD - entre as quais uma em um helicóptero, 8 câmera SSM (Super Slow Motion Câmera Super Lenta), 2 Hi Speed Cam (Câmera super rápida com até 2000 frames por segundo) e uma Spidercam (câmera montada sobre fios colocada encima do gramado e dirigida via Wirelles), além de 23 câmeras HD - (ver Imagem 1). Nos jogos realizados com tecnologia $8 \mathrm{~K}$ foram utilizadas apenas 13 câmeras, das quais 12 foram as F55 de Sony e uma 1 F65

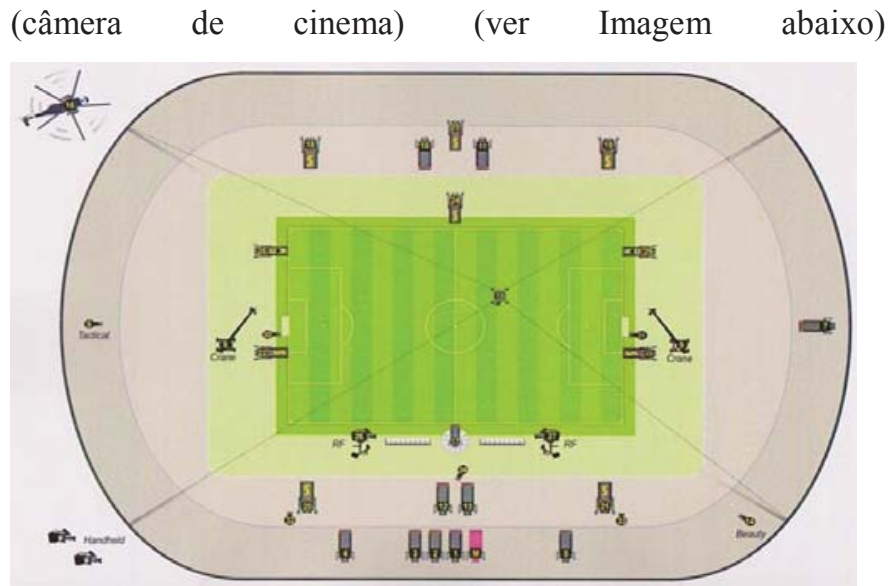

Imagem 1 - Fonte: EVS SPORTS - Congresso SET 2014

Plano de Câmeras para transmissões da FIFA durante a Copa do Mundo Brasil 2014 para a transmissão broadcast em HD

A seguir, o plano de câmeras utilizado para a transmissão realizada pela primeira vez na história da televisão em uma transmissão ao vivo em $4 \mathrm{~K}$ : 


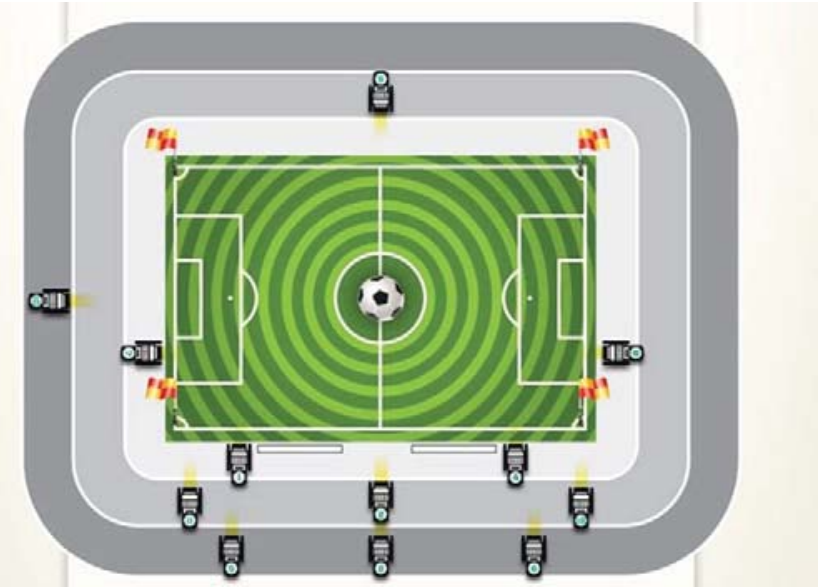

Imagem - 2 Fonte: Sony Brasil

Plano de câmeras utilizado pela FIFA para realização dos jogos em $4 K$ durante a Copa do Mundo

\section{O discurso como fenômeno de Produção de Sentido}

O discurso do futebol é um processo de produção de sentido, porque, segundo Verón, possui as suas características principais e gera sentido para os seus telespectadores. Toda a produção de sentido é necessariamente social: não se pode descrever nem explicar satisfatoriamente um processo significante, sem explicar suas condições sociais produtivas. Todo o fenômeno social é, numa das suas dimensões constitutivas, um processo de construção de sentido, qualquer que seja o seu nível de análise (VERÓN, 1996, p. 125).

Desta análise, podemos aferir que o "padrão FIFA" de transmissões é uma construção de sentido produzida por diversas opções retóricas e de sentido que são utilizadas na construção de uma transmissão esportiva ao vivo, e que as transmissões dos jogos realizados no Brasil pelas emissoras locais, seja TV Globo, TV Bandeirantes, Sportv, Fox Sports, ESPN Brasil - com as nuances próprias de cada emissora são construções de sentido diferentes as que a FIFA gerou durante a última Copa do Mundo, pois o posicionamento das câmeras, enquadramento e objetos de primeiro e segundo plano são diferentes dos utilizados pelas emissoras no Brasil. Também muito diferentes do sistema de captação das câmeras 4K. Sua maior resolução de imagem e quantidade de píxels torna desnecessária a captura por um grande número de câmeras. Desta forma, a edição (menos cortes de imagens) segue uma narrativa diferente criada pelo diretor de imagens, com planos de maior duração, menor influência no direcionamento da atenção do telespectador para os detalhes na composição da imagem, o que altera diretamente a narrativa do jogo em si e também a própria narração do locutor. A experiência do telespectador passa a ser mais próxima daquela que tem o espectador na arquibancada do estádio. Assim, temos o mesmo esporte, no mesmo estádio, mas com construções retóricas diferentes.

Se consideramos a Teoria dos Discursos Sociais (Verón, 1996), estaríamos frente a criações discursivas diferentes baseadas em contextos e discursos anteriores diferentes, cada um pensado e estruturado em base a outros discursos e outros olhares da mesma manifestação, o jogo de futebol. Isso acontece, entre outras coisas, pela parafernália tecnológica utilizada e pela disposição e quantidade de câmeras utilizadas para contar e criar o "discurso jogo de futebol". Esta parafernália sofreu grandes modificações na última Copa do Mundo, talvez as maiores dos últimos 20 anos quando foi introduzido o HD (High Definition) nas transmissões esportivas.

\section{Dimensões do discurso futebolístico}

Uma vez mostrada minimamente a parte técnica e, com esta, apenas a diferença no plano de câmeras desenhado pela FIFA, trabalharemos a dimensão cognitiva, pragmática e Passional (Greimas \& Courtês, 1979; Greimas e Fontanille, 1991) para mostrar as diferentes narrativas e como o discurso se transforma.

Como explicamos acima, o discurso é uma unidade de produção de sentido que gera significação. No caso analisado a significação muda por dois motivos. Primeiro porque as câmeras $4 \mathrm{~K}$ utilizadas geram nos telespectadores o que é denominado de "imersão". Nesse sentido, e antes de chegar às dimensões do discurso mediático, é importante referir que dentro desse discurso existem estruturas de significação que se manifestam na comunicação porque é no ato de comunicação, não acontecimento-comunicação, que o significado encontra o significante. (GREIMAS, 1973) 
Greimas \& Courtes (1979) trabalham o discurso a partir de três dimensões constitutivas que são a dimensão cognitiva, pragmática e passional. A estrutura cognitiva elementar tem sido descrita como a relação entre um sujeito e um objeto de conhecimento, estabelecida pelo enunciado. Os autores reconhecem a existência de uma dimensão cognitiva do discurso, constituída pela integração desses enunciados elementares, que pressupõe necessariamente a existência de uma dimensão pragmática, que lhe serve de referente interno e à qual é hierarquicamente superior. Assim, a dimensão cognitiva designa conhecimento, praxis, envolvimento, todas situações encontradas no discurso analisado, já que tanto o produtor como o telespectador precisam ter conhecimento sobre o jogo, praxis e envolvimento, isso não só no seu nível primário senão, também, complementários, já que esta dimensão aparece tanto na produção como na comunicação do saber. De fato, segundo os autores, deve haver quanto às instâncias cognitivas, pelo menos um sujeito encarregado da produção, um sujeito encarregado da transmissão e outro da recepção do saber, ainda que sejam investidos num único ator, ou em vários atores.

Lopes (1990, p. 53) afirma que "todo saber, para produzir-se, requer a existência de uma dimensão pragmática como referente; todo saber, para ser comunicado requer ter sido-previamente produzido" e que o nível da comunicação pressupõe o nível da produção do saber, que lhe é hierarquicamente inferior. No caso estudado, aferimos que nas transmissões experimentais realizadas durante a Copa do Mundo com tecnologia 4K com uma nova disposição de câmeras e equipamentos necessários para repetições, grafismo, enlaces satelitais etc. a dimensão cognitiva ficou no sujeito encarregado da produção e no encarregado da transmissão (neste caso, o mesmo consórcio TV Globo/FIFA), e que o seu modo de recepção do saber se encontrou com um novo discurso futebolístico. Consideramos que mudou a história contada, não só pela forma de ser produzida e recriada, mas também pelo dispositivo técnico que foi necessário ter para se receber esta nova forma, neste caso, uma TV 4K 60p e um settop box que pudesse decodificar o sinal emitido desde o Estádio do Maracanã.
Neste ponto, entramos na dimensão pragmática do discurso que indica o modo como este foi feito, desenvolvido e trabalhado. Afirmando que a televisão é uma das formas predominantes de criação da nossa representação do mundo, que ela nos permite imaginá-lo, estabelece parâmetros e mobiliza as atenções dos seus telespectadores inferimos que ela constrói discursos nos quais a realidade difundida pela TV opera como uma seleção e uma construção das informações que são emitidas. Isso permite afirmar que foi preciso criar uma praxis, um novo habitus (BOURDIEU, 1994) que permitisse aos produtores de sentido produzir o discurso futebolístico em 4K. Nesse sentido, temos um duplo problema, na produção e na recepção, porque para Bourdieu (1972), o gosto ou os gostos dos indivíduos, tende, neste sentido, a manifestar-se mediante a apropriação de determinados objetos ou a manifestar-se nas práticas em que os sujeitos se envolvem, traduzindo lógicas que funcionam enquanto classificadoras e distintivas, ou seja, traduzem as estratégias que os indivíduos adotam perante os sistemas classificatórios que interiorizam e que servem para que eles se posicionem socialmente, traduzindo igualmente a posição que atribuem a outros indivíduos ou grupos. Para Bourdieu o habitus é:

A necessidade interiorizada e convertida numa disposição que gera práticas significantes e percepções significadoras; é uma disposição geral de transferência que leva a cabo uma aplicação sistemática, universal - além dos limites do que foi diretamente aprendido - da necessidade inerente nas condições de aprendizagem. (Bourdieu, 1972, p. 170)

$\mathrm{Na}$ nova transmissão com novas câmeras, novos planos e um discurso parecido, mas não igual, a dimensão cognitiva passa por uma transformação, por uma modificação, já que o telespectador não adquiriu o habitus desse novo discurso e na sua dimensão cognitiva ele nem sempre poderá impor um ponto de vista sobre o objeto (Greimas \& Courtes, 1979) porque, se bem o conhece o discurso futebolístico, este mudou a sua estrutura narrativa e sua forma de exibição.

Ao passar de 35 para 13 câmeras e, sobretudo, a ter maior qualidade de imagem, mas menor capacidade de foco em movimento devido a maior distância focal e range dinâmico da imagem, foi necessário trabalhar com planos mais 
abertos das ações do jogo e resignar a espectacularidade do plano fechado com câmera super lenta para captar lances com planos mais abertos, mas com uma profundidade de campos imensamente maior. Outra grande diferença retórica na hora da construção do discurso foi a possibilidade de repetições dos grandes momentos do jogo. Pela quantidade de câmeras e a qualidade de imagem que estas captam, não foi possível gravar todas as câmeras ao mesmo tempo no sistema de replays montado na Unidade Móvel que produziu os jogos, foi preciso seleccionar o que gravar, como e onde isso poderia ser reproduzido, e por isso foi necessário mudar a praxis de produção e emissão e utilizar os recursos possíveis frente ao novo discurso.

Por outro lado, foi criado um grafismo especial para as transmissões, e ele também mudou a praxis tanto na hora de produzir como na de receber o discurso, não só pela dimensão e formato de vídeo gerado, senão também pela forma em que foi inserido o grafismo em $4 \mathrm{~K}$. A área de segurança (espaço que se deixa aos lados da imagem para o telespectador não perder a informação) para o grafismo teve de ser ampliada. $\mathrm{Na}$ transmissão HD o formato é de $16 \times 9$, nas transmissões em $4 \mathrm{~K}$ foi enviado um sinal em formato $17 \times 9$.

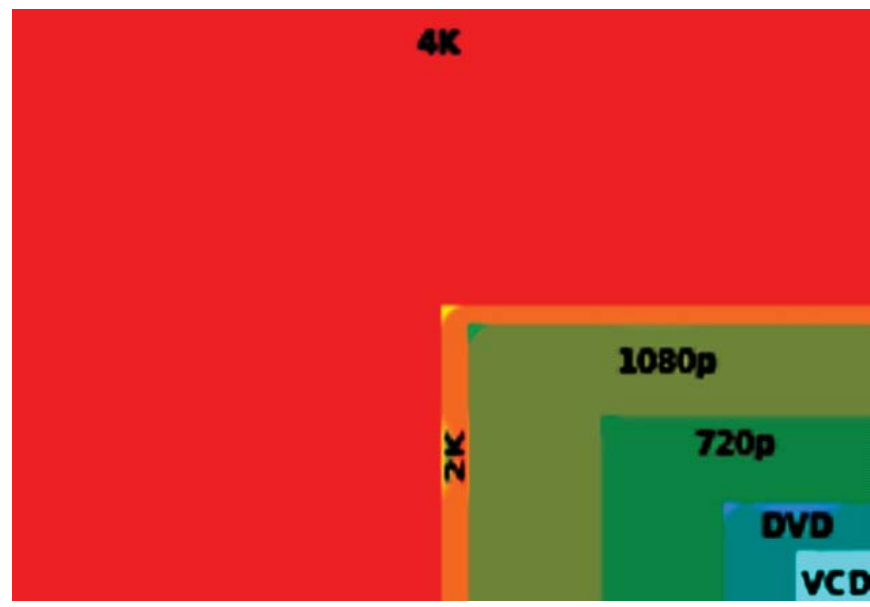

Imagem - 3 Fonte: SONY Brasil

Ainda é preciso aqui afirmar que outro ponto importante na recepção deste discurso aparece e se conforma com a nova realidade discursiva estabelecida. É a dimensão Passional, uma dimensão não controlada pelo telespectador e que se confronta com a decodificação do discurso unido à paixão pelo país, situação que não se explorará neste trabalho, mas que são importantes na hora de analisar o fenômeno.

De fato, a paixão concebida por Aristóteles aparece como uma contingência que provoca mudança na essência do sujeito. O filósofo afirma que ela foi criada pelo produtor de sentido (orador, no caso estudado por Aristóteles, em nosso caso, a FIFA) para comover o auditório. A paixão advém do Pathos e chega de forma abrupta ao receptor que se encontra em um estado contingente produzido pela influência externa.

Em Semiótica das paixões, Greimas e Fontanille

ampliam o conceito de paixão aristotélica, e a concebem como estados de alma de um sujeito que podem ser depreendidos a partir da análise de um texto, neste caso, poderíamos afirmar que o discurso futebolístico cria um novo estado da alma, um estado que pode ir do êxtase à frustração, dependendo do resultado e do envolvimento deste com o espectáculo. Pensamos que no discurso futebolístico a paixão se junta com a praxis, com o habitus do receptor/torcedor, neste caso uma nova praxis, uma nova forma de produzir e receber o discurso do futebol, uma nova forma de produzir que não muda a essência do discurso, mas sim as nuances dele.

Analisando o novo discurso futebolístico em 4K, poderíamos afirmar que aqui há uma mudança de contrato de Leitura, definição utilizada por Verón (199, p. 70). Nessa mudança, a dimensão passional torna-se fundamental, já que, sem dúvida, existe um contrato entre quem emite e quem assiste. $\mathrm{O}$ contrato de leitura é a relação existente entre o suporte (produção de TV) e o telespectador, como esses dois se vinculam e como é produzido este vínculo, um vínculo que mudou, porque mudaram algumas das características discursivas do modelo anterior, o do Padrão FIFA ao qual o telespectador estava habituado, e introduziu novas formas narrativas e retóricas.

\section{Conclusões}

$\mathrm{Na}$ atualidade, o mundo "da bola", um dos mais rentáveis até hoje para as emissoras de TV aberta e de TV paga, precisa encontrar novas formas de desfrutar do fenômeno para que este continue sendo fonte de receita e, com 
isso, de sustentação do modelo atual de negócio. Assim, na última Copa do Mundo Brasil 2014 realizada pela FIFA houve mudanças substanciais no discurso "futebolístico" e, com isso, do seu espetáculo, com a introdução da tecnologia $4 \mathrm{~K}-4$ vezes HD (High Definition). A introdução desta tecnologia mudou a retórica das narrativas das transmissões de futebol e de como a FIFA "padronizou” o espetáculo.

Mudou a forma de fazer técnica e retoricamente, mudou o enquadramento, produto dos sensores CMOS que não permitem determinadas tomadas em um evento ao vivo, a quantidade de câmeras no campo - passando de 32 na transmissão broadcast oficial para apenas 13 na transmissão $4 \mathrm{~K}$ e 5 na $8 \mathrm{~K}$ - e, sobretudo, a forma como se conta a historia do jogo.

O conceito de TV se está reinventando e o destino do discurso futebolístico televisado está mudando porque já não se pensa somente em TV aberta ou TV paga Premium, senão em novas plataformas e soluções que podem viabilizar o consumo deste discurso, até parece ser possível inferir que não só o discurso está mudando, mas também o espectador, que aos poucos se vai transformando em um usuário de múltiplas plataformas de vídeo e não um mero "tele"spectador sentado em frente à TV.

Nesse campo, parece que a tendência é uma maior qualidade de imagem, menos câmeras em campo e uma nova forma de olhar, que talvez, segundo alguns dizem, se concretize com a implantação no formato em $8 \mathrm{~K}$, onde o fenômeno imersivo da imagem poderá ser ainda maior e fazer com que o discurso futebolístico possa voltar a ser contado como no início das transmissões esportivas, com apenas uma câmera.

\section{Referências Bibliográficas:}

BOURDIEU, Pierre. (1972). La Distinction: Critique sociale du jugement. Paris: Les Éditions de Minuit.

Raisons Pratiques. Paris: Éditions du Seuil. 1994.

The aristocracy of culture. In D. Miller (Ed.), Consumption, critical concepts in the social sciencies (pp. 239-245). London: RouHedge, 2001.
FECHINE, Yvana. Gêneros televisuais: a dinâmica dos formatos. In: $\quad$ http://www.maxwell.vrac.pucrio.br/3195/3195.PDF. 2001. Acesso em 21 de fev. 2015, às $21 \mathrm{~h} 14 \mathrm{~m}$.

GIOVANNINI, Giovanni. Del pedernal al sicilio. Historia de los medios de comunicación masiva Buenos Aires: EUDEBA, 1987.

GREIMAS, Algirdas Julius \& FONTANILLE, Jacques. Semiótica das paixões. Trad. Maria José Coracini. São Paulo: Ática, 1993.

LOPES, Paulo Eduardo. Por um modelo unificado da cognição discursiva in Revista SIGNIFICAÇÃO Outubro/1990 No 8 e 9, página 49-62

MOURA, Fernando Carlos. A construção da identidade de uma comunidade imigrante portuguesa na Argentina (Escobar) e a comunicação social. Universidad de Lisboa FCHS: Tesis de doctorado en Ciencias de la Comunicación, 2010 .

Portugal Hoje: o papel dos programas de rádio na comunidade portuguesa da Argentina. In: H. Carreiras \& A. M. (Orgs.) Do Fado ao Tango. Os Portugueses na Região Platina. Lisboa: Editora Mundos Sociais, 2010.

Final da Copa do Mundo em 4K - IBC 2013 Parte I. Revista da SET, São Paulo, p. 42 - 68, 138, 2013.

Copa do Mundo em 4K por espectro. Revista da SET, São Paulo, p. 46 - 58, 144, 2014.

Novo Paradigma nas transmissões televisivas. A Copa do Mundo em 4K, XIV Congresso Internacional Ibercom 2015, 29 de março a 2 de abril, ECA/USP São Paulo, 2015

SARTORI, Giovanni. Homo Videns - Televisão e Póspensamento (S. Neto, Trans.). Lisboa: Ed. Terramar, 2000

VERÓN, Eliseo. La semiosis social. Fragmentos de una teoría de la discursividad. Barcelona: Gedisa, 1996.

WOLF, Mauro. Teorias da Comunicação. 5a ed. Lisboa: Editorial Presença, 2013. 
Los Efectos Sociales de los Media (Libro de Bolsillo ed.).

Madrid: Alianza Editorial, 2000.

WOLton, Dominique. Elogio do Grande Público: Uma teoria crítica da televisão. Porto: Editorial Asa, 2013.

Fernando Carlos Moura é Doutor em Ciências da Linguagem e Comunicação com especialidade em Comunicação e Cultura pela Universidade Nova de Lisboa, Portugal (2010). Diploma de doutorado reconhecido pela Universidade de São Paulo (USP) como doutor em Ciências da Comunicação na área de Estudo dos Meios e da Produção Mediática. (2012). Experiência na área de Comunicação, com ênfase em Ethnic Minority Media, rádio e televisão. Interesse em migrações europeias, basicamente a portuguesa ao Cone Sul (Argentina, Brasil e Uruguai). Especialista em implantação de TV Digital no Brasil e América Latina com trabalhos realizados para a Revista da SET (Sociedade Brasileira de Engenharia de Televisão), onde desde 2013 é editor-chefe, nessa área e nas novas tecnologias de TV como $4 \mathrm{~K}$ e $8 \mathrm{~K}$, transmissões televisivas e grandes eventos esportivos. Ainda é pesquisador do Centro de Investigação Media e Jornalismo (CIMJ), Faculdade de Ciências Sociais e Humanas, Universidade Nova de Lisboa (UNL). Email: fernandocarlosmoura@gmail.com

Cite this article:

C. Moura, F.; 2015. As mudanças nas transmissões de TV com a chegada da Super Alta Definição. SET EXPO PROCEEDINGS. ISSN Print: 2447-0481.ISSN Online: 2447-049X. v.1.doi: 10.18580/setep.2015.1.10 Weblink: http://dx.doi.org/10.18580/setep.2015.1.10 